\title{
LETTERS
}

\section{COVID Towers: low- and medium-intensity care for patients not in the ICU}

In their CMAJ article, Arya and colleagues ${ }^{1}$ mention the ways in which Italy has dealt with the coronavirus disease 2019 (COVID-19) pandemic: the authors' statement that "many older patients with comorbidities being denied access to critical care resources" does not correspond to reality.

In Italy, in addition to efforts to standardize care in intensive care units (ICUs) for the most critical patients who are often relatively young, many hospital beds have been converted to offer a lowto-medium intensity of care to most patients, even those who are older and frail. We can affirm that no one was denied treatment because of age and comorbidity in our region of Italy. ${ }^{2}$

For these patients with COVID-19, the traditional model of clinical care is not suitable in these times of great demand on health care services. Here, we will outline the general guidelines that oriented our effort to improve the clinical approach to these patients, based on our experience.

In Lombardy, a region of northern Italy, the COVID-19 outbreak has been catastrophic. In 4 weeks, the virus has overcrowded all hospitals, and most wards have had to be converted into COVID-19 wards. Brescia, a city east of Milan and the capital of a province with 1.2 million inhabitants, has had 6300 cases of COVID-19 between Feb. 22 and Mar. 26 and, of these, 1000 died. About 53\% (2265 out of 4200) of hospital beds have been converted to the treatment of patients with COVID-19-related pneumonia, mainly in acute medical units (called COVID Towers) and in ICUs ( $8.5 \%$ of dedicated beds). All patients arrive from the emergency department and COVID Tower admission is warranted if a patient has respiratory failure and needs to be admitted to hospital with a level of care between ordinary and intensive. In this scenario, there are 3 groups of patients according to the phenotypic classification of COVID-19-related pneumonia as defined by the Società Italiana di Anestesia Analgesia Rianimazione e Terapia Intensiva (SIAARTI): patients in stage III, partial pressure of oxygen in arterial blood $\left(\mathrm{PaO}_{2}\right) /$ fraction of inspired oxygen $\left(\mathrm{FiO}_{2}\right)>300 \mathrm{~mm} \mathrm{Hg}$; in stage IV, mild acute respiratory distress syndrome (ARDS), $200<\mathrm{PaO}_{2} / \mathrm{FiO}_{2}<300 \mathrm{~mm} \mathrm{Hg}$; and in stage IV, moderate ARDS, $100<\mathrm{PaO}_{2} /$ $\mathrm{FiO}_{2}<200 \mathrm{~mm} \mathrm{Hg}{ }^{3}$

A major effort has been made to standardize care in ICUs where the most critical patients, who have a greater risk of death and are often younger, are admitted. ${ }^{4}$ However, little has been done to structure the clinical approach to treatment of most patients in COVID Tower units (low-to-medium intensity of care). For these patients, a traditional model of clinical care is not suitable. Until definitive clinical data are available, it is necessary to rely on experience to improve the clinical approach to these patients.

In our experience with patients with COVID-19 who were not admitted to the ICU (in our hospitals we manage about 430 beds for patients with COVID-19); the mean age of these patients is 69.8 years. Even with comorbidities (e.g., coronary artery disease, hypertension and diabetes), before infection they had good functional status and most patients were active without substantial-disabilities.

The infection is easy to diagnose on the basis of clinical symptoms and simple tests (e.g., chest radiography/ computed tomography, blood gas analysis and laboratory tests such as white blood cell count, lymphocyte count, hemoglobin, urea and creatinine, serum albumin and others). Treatment, even when empirical (e.g., chloroquine), is provided by protocol: antibiotics, antivirals, chloroquine, corticosteroids, heparin for deep vein thrombosis prophylaxis and tocilizumab. Oxygen therapy is given by high-flow nasal cannula and noninvasive ventilation.

Physicians, most of whom are not infectious disease specialists, internists or intensivists, are facing an unknown disease with no previous experience.
They need to be given clear and simple guidelines.

Monitoring has to be basic: fever and dyspnea, respiratory rate, oxygen saturation, weakness (inability to get up from a chair without help) and insomnia. Monitoring has to be scheduled and frequent because of sudden changes that require consideration of transfer to the ICU.

However, most patients do not benefit from intubation: frail and older patients will likely not survive the prolonged intubation required to recover from COVID19-related pneumonia.

Length of stay (14 days) and mortality rate $(28 \%)$ are high in patients admitted to the COVID Towers. The mean age of patients who have died is 79 years. Most physicians and nurses are not prepared for such a high death rate and, for many, it is often physically and psychologically unbearable.

A simple and clear training program, a daily meeting with team members and constant psychological support are the basis for maintaining a high level of care and avoiding burn out of staff.

Because of the contagiousness of COVID-19, being close to patients is not easy, and it is difficult to understand their mood when their faces are masked. Patients are usually anxious and scared, and untrained physicians may have difficulties reassuring patients and their relatives. The use of technology (video or phone chat) can help communication with family members and alleviate the suffering of both.

With these simple guidelines it has been possible to manage a huge flow of patients. Traditional hospital departments have been radically reorganized and physicians of various specialties and training have been involved. We do not know if other models could be better, but this is how we have dealt with an emergency of overwhelming magnitude, and offered patients the comfort of a hospital bed.

The COVID-19 outbreak requires radical changes in the care of patients with the disease. ${ }^{5}$ Most of these patients are admitted to hospital in COVID-19 wards. A 
new and specific way of care is necessary. Our experience today may unfortunately be that of many other hospital colleagues tomorrow. It is our hope that sharing these notes will be of help to them.

\section{Renzo Rozzini MD}

Director of the geriatrics department, Fondazione Poliambulanza Istituto

Ospedaliero, Brescia, Italy

\section{Angelo Bianchetti MD}

Head of the medicine and rehabilitation department, Istituto Clinico Sant'Anna Gruppo San Donato, Brescia, Italy

Cite as: CMAJ 2020 April 27;192:E463-4. doi: $10.1503 / \mathrm{cmaj} .75334$

\section{References}

1. Arya A, Buchman S, Gagnon B, et al. Pandemic palliative care: beyond ventilators and saving lives. CMAJ 2020;192:E400-4.

2. Onder G, Rezza G, Brusaferro S. Case-fatality rate and characteristics of patients dying in relation to COVID-19 in Italy. JAMA 2020 Mar. 23; [Epub ahead of print]. doi:10.1001/jama.2020.4683.

3. Percorso assistenziale per il paziente affetto da COVID-19: Sezione 1 - Procedure area critica. Roma: Società Italiana di Anestesia Analgesia Rianimazione e Terapia Intensiva (SIAARTI); 2020. Available: www.siaarti.it/SiteAssets/News/ COVID19\%20-\%20documenti\%20SIAARTI/Percorso \%20COVID-19\%20-\%20Sezione \%201\%20\%20-\%20 Procedura\%20Area\%20Critica.pdf (accessed 2020 Apr. 3).

4. Grasselli G, Pesenti A, Cecconi M. Critical care utilization for the COVID-19 outbreak in Lombardy, Italy: early experience and forecast during an emergency response. JAMA 2020 Mar. 13; [Epub ahead of print]. doi:10.1001/jama.2020.4031.

5. Willan J, King AJ, Jeffery K, et al. Challenges for NHS hospitals during COVID-19 epidemic. BMJ 2020;368:m1117.

Competing interests: None declared. 